\title{
New In-situ Synthesis Method of Magnesium Matrix Composites Reinforced with TiC Particulates
}

\author{
Zhang Xiuqinga*, Liao Lihua ${ }^{\mathrm{b}}$, Ma Naiheng ${ }^{\mathrm{b}}$,Wang Haowei ${ }^{\mathrm{b}}$ \\ ${ }^{\mathrm{a}}$ Faculty of Metal Materials Engineering, College of Resource and Environment Engineering, \\ East China University of Science and Technology, 379 Mail Box, \\ $n^{\circ}$ 130, Meilong Rd., 200233 Shanghai City, China \\ ${ }^{\mathrm{b}}$ The State Key Lab of Metal Matrix Composites, Shanghai Jiao Tong University, Shanghai
}

Received: June 7, 2005; Revised: October 24, 2006

\begin{abstract}
Magnesium matrix composites reinforced with TiC particulates was prepared using a new in-situ synthesis method of remelting and dilution technique. And measurements were performed on the composites. The results of $\mathrm{x}$ ray diffraction $(\mathrm{XRD})$ analysis confirmed that $\mathrm{TiC}$ particulates were synthesized during the sintering process, and they retained in magnesium matrix composites after the remelting and dilution processing. From the microstructure characterization and electron probe microanalysis (EPMA), we could see that fine TiC particulates distributed uniformly in the matrix material.
\end{abstract}

Keywords: magnesium matrix composites, in-situ synthesis technique, TiC particulates

\section{Introduction}

Magnesium alloys is promising materials because of their low density, high specific strength, high specific stiffness, good dimensional stability and high damping capacity. The use of magnesium alloys in automobile parts is predicted to increase globally at an average rate of $15 \%$ per year ${ }^{1}$. But the ultimate tensile strength (UTS) of magnesium alloys is low, and they can not be applied under high temperature. Comparative to magnesium alloys, magnesium matrix composites is an excellent candidate because of its higher specific stiffness, higher specific strength and good elevated temperature creep properties $^{2}$. Presently, magnesium matrix composites is synthesized using ex-situ synthesis technology such as powder metallurgy, stir casting, pressure infiltration etc. But the size of reinforcements in the composites is large, which leads to a limited improvement of mechanical properties. Manoharan et al. ${ }^{3}$ prepared elemental magnesium and magnesium-silicon carbide composites using the methodology of fluxless casting followed by hot extrusion. The results of ambient temperature tensile testing on the extruded $\mathrm{Mg}$ and $\mathrm{Mg} / \mathrm{SiC}$ samples revealed that elastic module of the composites increases only with the increasing of $\mathrm{SiC}$ particulates, and ultimate tensile strength and ductility of the composites reduce. Hassan and Gupta ${ }^{4}$ synthesized commercially pure magnesium reinforced with $3.2 \mathrm{vol} \%$ of nickel. Mechanical properties characterization revealed that the presence of nickel as reinforcement led to a significant increase in elastic modulus of the composites, but a limited increase in $0.2 \%$ yield strength and UTS of the composites. Trojanova et al. ${ }^{5}$ prepared $\mathrm{Mg}-1 \% \mathrm{Al}_{2} \mathrm{O}_{3}$ materials using powder metallurgy technique. Only the damping capacity of the materials increased due to the improvement of dislocation density. In summary, the mechanical properties of metal matrix composites (MMCs) prepared by ex-situ synthesis technique improved little because of the large size of reinforcement and bad interface between magnesium matrix and reinforcements.

Compared to those ex-situ synthesis techniques, in-situ synthesis method is a new technique to prepare composites owing to many advantages, e.g. fine reinforcements, clean interface between matrix and reinforcement and good mechanical characterization ${ }^{6,7}$. Wang et al. ${ }^{8}$ synthesized magnesium-based composites reinforced by in-situ particulates. The results showed that mechanical properties of the composites increase much. But the reaction of Al-Ti-C perform in molten magnesium is precarious and uncontrollable. So we must research other in-situ synthesis methods to prepare magnesium matrix composites. Remelting and dilution (RD) technique is one of the in-situ synthesis methods. The RD technique contains two steps. Prefabricated block that consists of reinforcements is prepared firstly, and then prefabricated block is diluted into metal matrix melt to synthesize composites. RD technique is controlled easily, and it can be wide applied in industry field, which is advantageous to fabricate magnesium matrix composites compared to SHS reaction technology. Some metal matrix composites, for example $\mathrm{C}_{\mathrm{p}} / \mathrm{Al}-\mathrm{Si}_{-} \mathrm{Mg}^{9}$, were successful prepared using RD technique. Until now, magnesium matrix composites have not been synthesized using this technique.

Accordingly, the primary aim of the present work was to in-situ synthesize magnesium matrix composite reinforced with TiC ceramics particulate using RD technique. And then magnesium matrix composites were examined by $\mathrm{x}$ ray diffraction (XRD), scanning electron microscope (SEM), energy dispersive $\mathrm{x}$ ray detector (EDX) and electron probe microanalysis (EPMA).

\section{Experimental Procedures}

In this study, magnesium was used as the base materials. Aluminum, titanium and graphite powder were used as base materials of prefabricated block. Firstly, aluminum, titanium and graphite powder whose weight percentage were $50,37.5$ and $12.5 \%$ were mixed for 8 hours using ball mill under argon atmosphere protection. The weight ratio of ball and powder is 5:1. Subsequently, the mixed powder reacted at $1400 \mathrm{~K}$ in high frequency furnace under argon atmosphere after they had been extruded to cylinder $(\Phi 30 \mathrm{~mm}$ x $50 \mathrm{~mm}$ ) under $15 \mathrm{MPa}$ presses. Magnesium was superheated to $1023 \mathrm{~K}$ under $\mathrm{SF}_{6}+\mathrm{CO}_{2}$ gas atmosphere protection in a steel crucible. Then prefabricated block was put into magnesium melts according to $8 \%$ weight percentages of $\mathrm{TiC}$ particulates in magnesium matrix composites. Then the mixed melts was maintained for 10 minutes at $1023 \mathrm{~K}$. Then the superheated slurry was stirred by two blades steel stirrer at the speed of $200 \mathrm{r} / \mathrm{min}$ to facilitate the incorporation 
and uniform distribution of reinforcement particulates in the metallic matrix. Finally, the mixed melts was poured into metal mould to synthesize 8 wt. (\%)TiC/AZ91 composites.

In order to identify the primary reaction products and the phase of magnesium matrix composites, XRD analyses were carried out. Philip S-52 scanning electron microscope and EPMA were applied to determine the size and distribution of $\mathrm{TiC}$ particulates.

\section{Results and Discussion}

\subsection{Results of phase analysis}

During the sintering process, the Al-Ti-C powder system reacted. The reactive equation and their reactive free energies at $1400 \mathrm{~K}(\Delta \mathrm{G})$ were listed as follows ${ }^{10}$ :

$$
\begin{array}{ll}
3 \mathrm{Al}+\mathrm{Ti} \rightarrow \mathrm{TiAl}_{3} & \Delta \mathrm{G}=-3.724 \mathrm{~kJ} / \mathrm{mol} \\
\mathrm{TiAl}_{3}+\mathrm{C} \rightarrow 3 \mathrm{Al}+\mathrm{TiC} & \Delta \mathrm{G}=-74.02 \mathrm{~kJ} / \mathrm{mol} \\
\mathrm{Ti}+\mathrm{C} \rightarrow \mathrm{TiC} & \Delta \mathrm{G}=-167.72 \mathrm{~kJ} / \mathrm{mol}
\end{array}
$$

It was presumable form these reaction equations that the mixed powders reacted as the reactive equation: $\mathrm{Al}+\mathrm{Ti}+\mathrm{C}=\mathrm{Al}+\mathrm{TiC}$ ideally. So the final products of mixed powder were $\mathrm{TiC}$ and aluminum ideally.

The XRD results corresponding to magnesium matrix composites and prefabricated block were shown in Figure 1. The results revealed the presence of TiC phase in composites and prefabricated block. Alumina was discovered in the prefabricated block for aluminum was oxidized during mixing process and sintering process (as shown in Figure 1a)). Subsequently, alumina disappeared in magnesium matrix composites due to its poor wettability with magnesium matrix. The presence of $\mathrm{Mg}_{17} \mathrm{Al}_{12}$ phase in the composites sample was identified, as showed in Figure 1b. During solidifying process, aluminum diffused into magnesium melts and formed $\mathrm{Mg}_{17} \mathrm{Al}_{12}$ phase after reacted with magnesium. The presence of $\mathrm{Mg}_{17} \mathrm{Al}_{12}$ phase in the composites sample was revealed (as shown in Figure 1).

\subsection{Microstructure characterization}

Microstructure characterization conducted on prefabricated block and magnesium matrix composites was discussed in terms of size and distribution of $\mathrm{TiC}$ particulates. The results of scanning electron micrographs revealed a uniform distribution of $\mathrm{TiC}$ particulates and the fine size of TiC particulates (as shown in Figure 2). Microstructure characterization of prefabricated block consists of white piece, grey structure and white particulates whose size is about $0.5-1.0 \mu \mathrm{m}$. For the three zones, element contents analyses were made. The results were listed in Table 1. According to the results, it was confirmed that the white piece is aluminum, the grey structure is mixed with aluminum and $\mathrm{TiC}$ particulates, and the white particulates is $\mathrm{TiC}$ particulates. Aluminum acted as a medium to accelerate the reaction of titanium and graphite during sintering process. The uniform distribution and the fine size of reinforcement in prefabricated block were also due to the high efficiency mixing of ball mill.

After prefabricated block has been put into magnesium melt, aluminum and TiC particulates diffuse into magnesium melt uniformly. During solidifying process, aluminum reacted with magnesium to synthesize $\mathrm{Mg}_{17} \mathrm{Al}_{12}$ phase. TiC particulates remained in magnesium matrix uniformly and parts of them were pushed into grain boundary. So it was found that the presences of little agglomeration of TiC particulates are adjacent to $\mathrm{Mg}_{17} \mathrm{Al}_{12}$ phase (as shown in Figure 2b and Figure 3). However, the uniform distribution of $\mathrm{TiC}$ particulates in $\mathrm{Mg}_{17} \mathrm{Al}_{12}$ phase was also discovered (as shown in Figure $3 \mathrm{~b}$ ). It was also estimated from Figure 3 that the size of TiC particulates is about

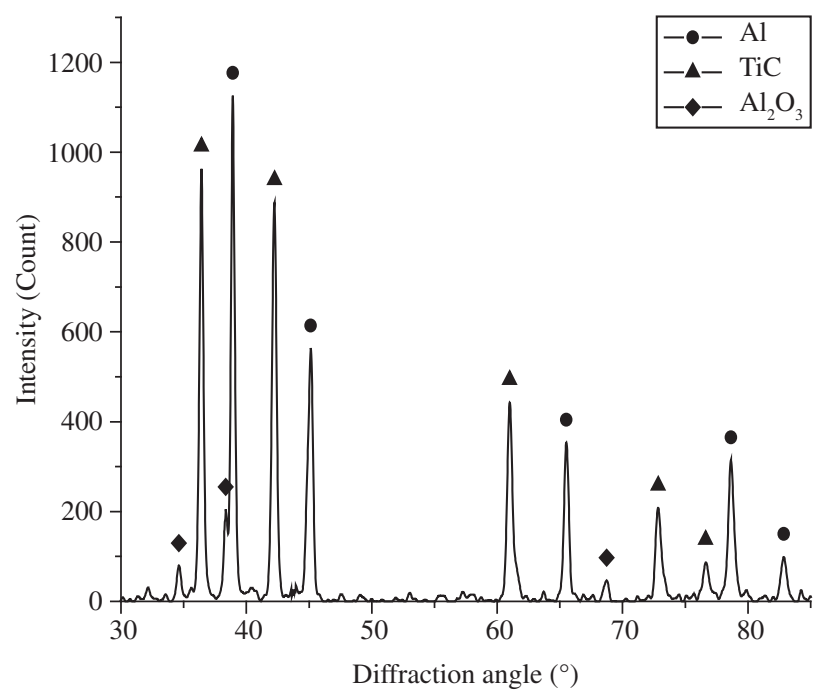

(a)

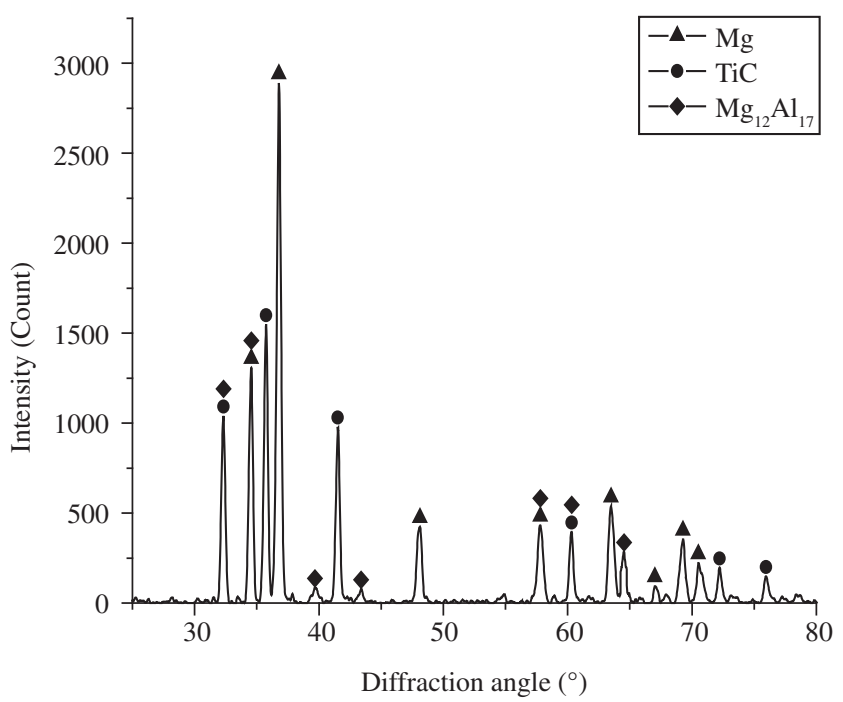

(b)

Figure 1. X ray diffraction patterns of samples a) prefabricated block; and b) magnesium matrix composites.

Table 1. Element contents analysis in different zone of Al-Ti-C sintered blocks.

\begin{tabular}{lrrrr}
\hline \multirow{2}{*}{ Zone } & \multicolumn{5}{c}{ Element contents (wt. (\%)) } \\
& $\mathrm{Al}$ & $\mathrm{Ti}$ & \multicolumn{1}{c}{$\mathrm{C}$} & $\mathrm{O}$ \\
\hline White piece & 95.6 & 2.1 & 1.5 & 0.8 \\
Grey structure & 55.7 & 34.6 & 8.6 & 1.1 \\
White particulates & 5.1 & 74.6 & 18.5 & 1.8 \\
\hline
\end{tabular}

0.5-1.0 $\mu \mathrm{m}$. TiC particulates dispersed well due to its fine wettability with magnesium matrix and fine size ${ }^{11}$. Uniform distribution of TiC particulates obtained in the present study could be mostly attributed to the judicious stirring. The judicious selection of stirring parameters is important, which ensured uniform incorporation of reinforcements particulates in magnesium matrix melt.

Energy dispersive $\mathrm{x}$ ray detector (EDX) analysis of magnesium matrix composites was conducted on square area in Figure $2 b$. The results of EDX analysis revealed that there are 6.43 wt. (\%) titanium, 


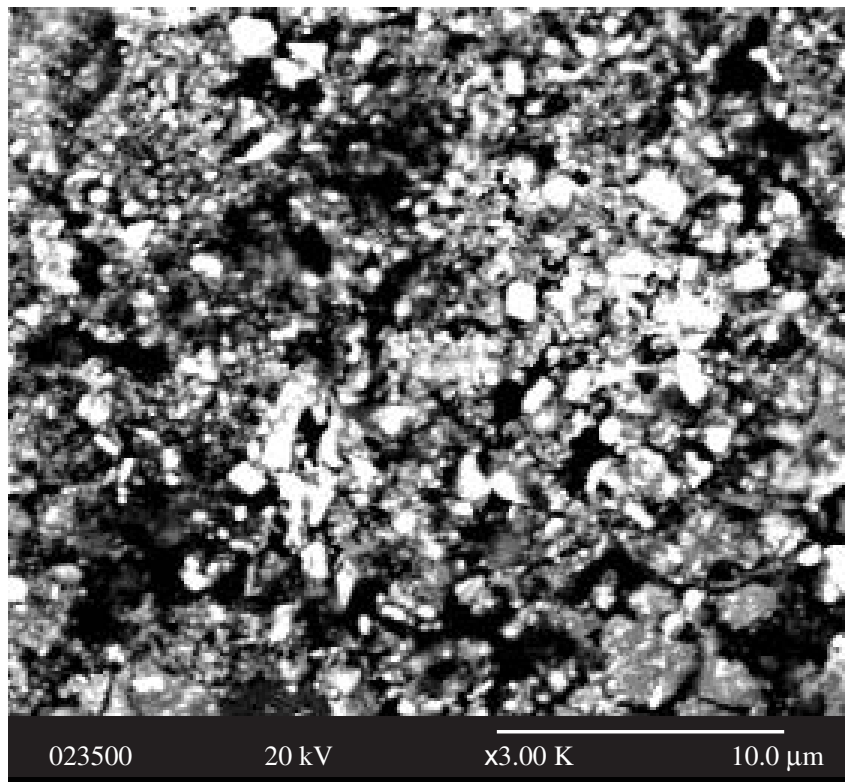

(a)

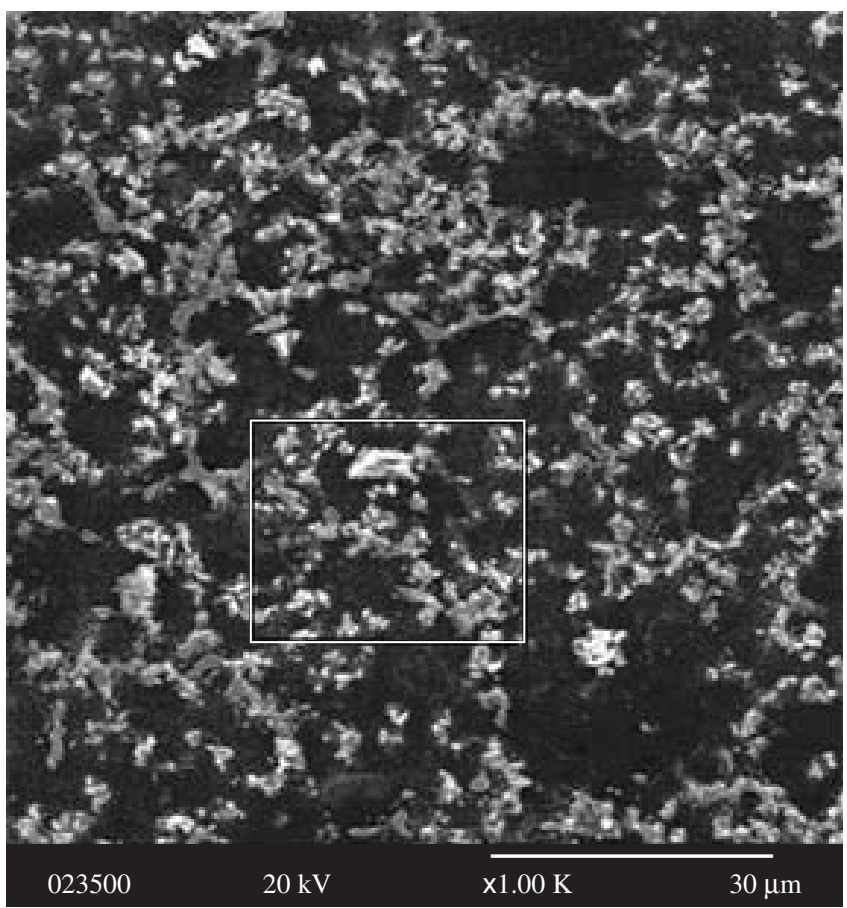

(b)

Figure 2. Scanning electron microscope (SEM) analysis of samples a) prefabricated block; and b) magnesium matrix composites.

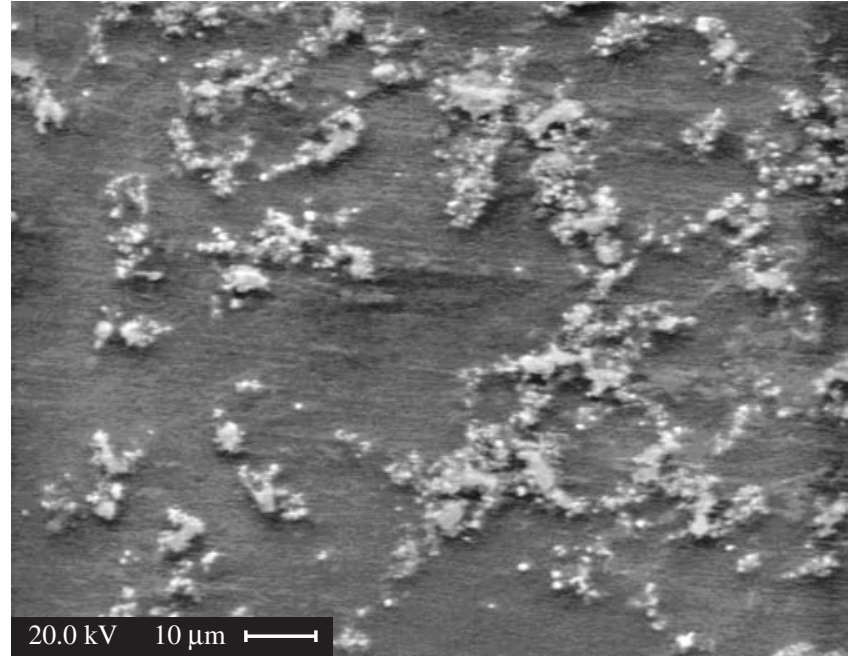

(a)

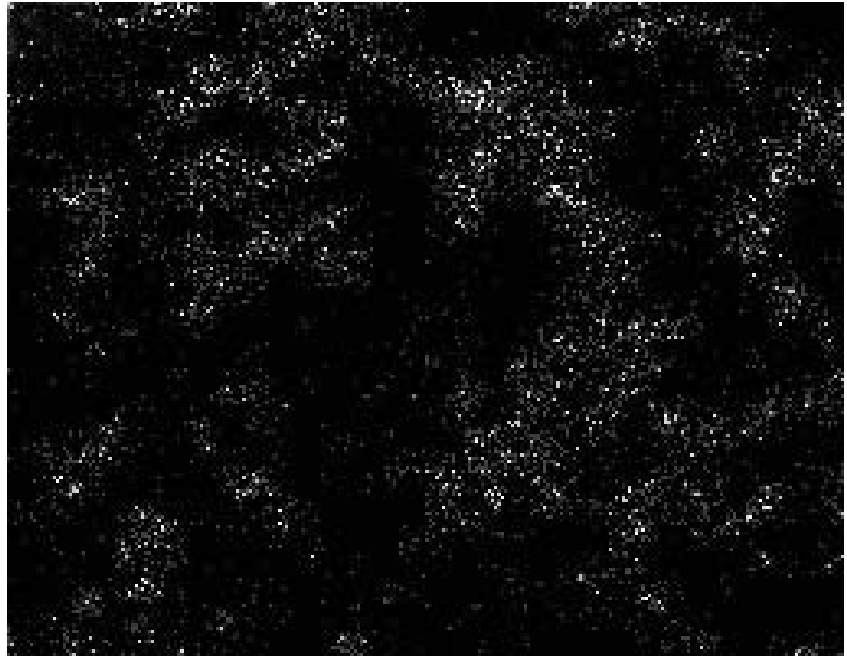

(b)

Figure 3. SEM analysis of magnesium matrix composites a) pattern; and b) Tik ${ }_{\alpha}$ area scanning.

1.58 wt. (\%) graphite and 8.36 wt. (\%) aluminum in magnesium matrix composites (as shown Figure 4). It could be calculated that there is about 8.01 wt. (\%) TiC particulates in magnesium matrix composites for titanium exist by mean of TiC mainly. There is about $3.37 \%$ volume percentage of $\mathrm{TiC}$ particulates in magnesium alloy matrix by mathematic calculation, which is consilient with numerical estimate about Figure 3. There is 8.36 wt. (\%) aluminum in the magnesium matrix composites, which is consilient with that of AZ91 magnesium alloy.

\section{Conclusion}

Magnesium matrix composites reinforced by TiC ceramic particulates were in-situ synthesized successfully using RD technique. Final products of prefabricated block are TiC and aluminum ideally, and the size of TiC particulates is $0.5-1.0 \mu \mathrm{m}$. The uniform distribution of TiC particulates in magnesium matrix is identified with microstructural characterization and EPMA, which could be mostly attributed to judicious stirring, fine reinforcements and good wettability between magnesium matrix and $\mathrm{TiC}$ particulates. 


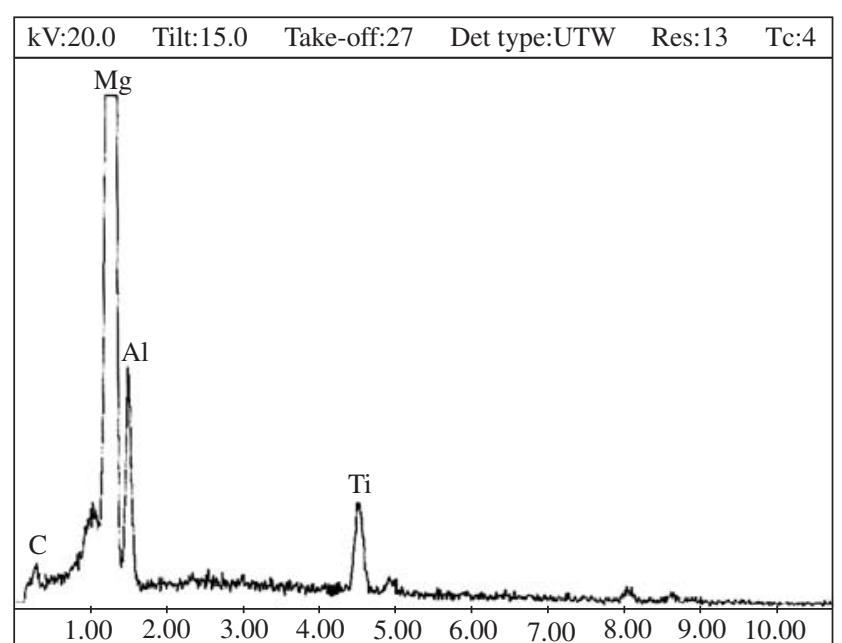

Figure 4. EDX analysis of magnesium matrix composites.

\section{Acknowledgment}

The authors thank the State Key Lab of Metal Matrix Composites of Shanghai Jiao Tong University for providing the XRD, SEM and EPMA testing.

\section{References}

1. Luo Alan A. Recent magnesium alloy development for automotive power train applications. Materials Science Forum. 2003; 419-422(1):57.
2. Smoot Perry R. High specific modulus magnesium matrix composite. National SAMPE Technical Conference, Advanced Materials: Looking Ahead to the 21st Century, Boston, MA, USA. 1990; 22:825-833.

3. Manoharan M, Lim SCV, Gupta M. Application of a model for the work hardening behavior to $\mathrm{Mg} / \mathrm{SiC}$ composites synthesized using a fluxless casting process. Materials Science and Engineering A. 2002; A333(1-2):243.

4. Hassan SF, Gupta M. Development of a novel magnesium/nickel composite with improved mechanical properties. Journal of Alloys and Compounds. 2002; 335(1-2):L10.

5. Trojanova Z, Lukac P, Ferkel H, Mordike BL, Riehemann W. Stability of microstructure in magnesium reinforced by nanoscaled alumina particles. Materials Science \& Engineering A. 1997; A234(23):98.

6. Nakata, Hiromichi, Choh, Takao, Kanetake, Naoyuki. Fabrication and mechanical properties of in situ formed $\mathrm{TiC}_{\mathrm{p}} / \mathrm{Al}$ composites by the solidliquid interfacial reaction. First International Conference on Processing Materials for Properties, Honolulu, HI, USA. 1993; p. 999-1002.

7. Xun ZQ, Zhang D, Ding J, Fan TX, Lv WJ. Research Development of In-situ Magnesium Matrix Composite4s and the In-situ Reaction Thermodynamics of the Reaction Systems. Materials Science and Engineering. 2002; 20(4):579.

8. Wang HY, Jiang QC, Li X, Wang JG. In situ synthesis of TiC/Mg composites in molten magnesium. Scripta Materialia. 2003; 48(9):1349.

9. Pillai UTS, Pai BC, Kelukutty VS, Satyanarayana KG. Pressure die cast graphite dispersed Al-Si-Mg alloy matrix composites. Materials Science \& Engineering A. 1993; A169(1-2):93.

10. Ye DL. Thermodynamics date handbook of practical inorganic matter. Beijing: Metallurgical Industry Press; 1981. p. 1.

11. Contreras A, Leon CA, Drew RAL, Bedolla E. Wettability and spreading kinetics of Al and Mg on TiC. Scripta Materialia. 2003; 48(12):1625. 